\title{
Voltammetric method for the quantification of cadmium using non- commercial electrodes and minimal instrumentation
}

\author{
Baeza Reyes ${ }^{3}$ \\ 1 Universidad de Oriente, Faculty of Natural and Exact Sciences, Sede Antonio Maceo, Santiago de Cuba, Cuba \\ 2 Empresa Nacional de Análisis y Servicios Técnicos, 18401 Las Palmas Av, Havana, Cuba \\ 3 Universidad Nacional Autónoma de México, 33 República de Brasil St., Ciudad de México, México \\ + Corresponding author: Javier Ernesto Vilasó Cadre, e-mail address: javiere@uo.edu.cu
}

Javier Ernesto Vilasó Cadre ${ }^{1+}$, Alejandro Céspedes Martínez², María de los Ángeles Arada Pérez¹, José Alejandro

\section{ARTICLE INFO}

Article history:

Received: September 5, 2018

Accepted: December 13, 2018

Published: January 28, 2019
Keywords:

1. voltammetry

2. cadmium

3. non-commercial graphite electrodes

4. minimal instrumentation

ABSTRACT: A voltammetric method for the cadmium quantification was developed using minimal instrumentation. A manual homemade potentiostat for linear voltammetry was used. An Ag reference electrode and auxiliary and working electrodes of writing graphite were employed for the electroanalysis. The electrolytic conditions for the quantification were stablished. Linearity, detection and quantification limits, precision and accuracy were evaluated. The conditions for the quantification were $\mathrm{KCl} 1 \mathrm{~mol} \mathrm{~L}^{-1}$ as supporting electrolyte and $\mathrm{pH}$ 5. The range of quantification was from $10^{-3}$ to $1.5 \cdot 10^{-2} \mathrm{~mol} \mathrm{~L}^{-1}$. The linear correlation (r), determination $\left(\mathrm{R}^{2}\right)$ and adjusted $\left(\mathrm{R}^{2}\right.$ adj.) coefficients were $0.9986,0.9972$ and 0.9970 . The detection and quantification limits were $3 \cdot 10^{-4}$ mol L $\mathrm{L}^{-1}$ and $10^{-3} \mathrm{~mol} \mathrm{~L}{ }^{-1}$. Results showed an acceptable repeatability, with coefficients of variation from 1.5 to $5.8 \%$ depending on the concentration. Uncertainty associated with the cadmium concentration was in the range of $1.2 \cdot 10^{-4}$ to $7 \cdot 10^{-5} \mathrm{~mol} \mathrm{~L}^{-1}$, diminishing with the increasing of the concentration. A good accuracy was observed, with recoveries between 86.84 and $109.64 \%$.

\section{Introduction}

Voltammetry is an electroanalytical method based on the measurement of the current intensity during an electrolysis provoked by a controlled variable of potential over time. Voltammogram is a current-potential curve that shows the current increase due to analyte diffusion to and reaction on the electrode surface. This is caused by the concentration gradients between the bulk solution and the electrode. Voltammetric analysis is simple and not destructive; sample treatments are unnecessary in many cases. Furthermore, voltammetry techniques allow speciation and simultaneous determination ${ }^{1-3}$. This method has been widely used in metal quantification in different samples ${ }^{4-8}$.

Cadmium is one of the most monitored metals in the environment and wastewaters. Cadmium control is important due to its wide industrial applications, but its presence in ecosystems generates significant effects. This metal is used in batteries and as additive for plastics and glasses; it is also employed for galvanization and coating of surfaces due to its resistance to corrosion. Moreover, cadmium works as mordant in tincture and impression of textile materials, among other applications. However, cadmium compounds are toxic even in low concentrations. They may cause renal problems, infertility, immunologic and nervous affliction, cancer, and others ${ }^{9}$. Cadmium 
is easily bioaccumulated by fish, crustaceans and plants $^{8,10,11}$. Electrochemical reduction of cadmium may be used for its voltammetric quantification. The reaction of the process is provided in Equation 1.

$$
\mathrm{Cd}^{2+}{ }_{(\mathrm{ac})}+2 \mathrm{e}^{-}=\mathrm{Cd}_{(\mathrm{s})}
$$

Although voltammetry is cheaper than other methods of instrumental analysis, commercial instrumentation for its development is inaccessible for many laboratories of low economic resources. Some researchers have shown that construction of instrumentation for electrochemical methods is possible, from selective electrodes ${ }^{12,13}$ to potentiostats $^{14-16}$. A non-commercial instrumentation may be considered as minimal when it consists of the basic components to generate an electrochemical process. Voltammetric determination of cadmium has been reported ${ }^{7}$, however, the quantification using non-commercial instrumentation has not been widely reported. Bearing in mind this context, the objective of this work is to evaluate the analytic parameters for the voltammetric quantification of cadmium by using non-commercial electrodes and a minimal instrumentation potentiostat reported by the authors ${ }^{17}$. For future application of the method, the concentration ranges of the determinations have been selected in correspondence with the common amount of cadmium in the solution from the digestion of $\mathrm{Ni}-\mathrm{Cd}$ rechargeable batteries ${ }^{18}$.

\section{Materials and methods}

\subsection{Electrochemical instrumentation and chemical reagents}

A homemade minimal instrumentation manual micropotentiostat for linear sweep voltammetry was employed to develop the voltammetric method. The scheme of the circuit is shown in the Figure $1^{17}$. This consists of two parallel circuits. One allows the measurement the current between the working electrode and the auxiliary electrode. The other allows to measure the virtual potential between the working electrode and the reference. The potential sweep is made using a rheostat, which causes a potential fall through the electrolytic cell.

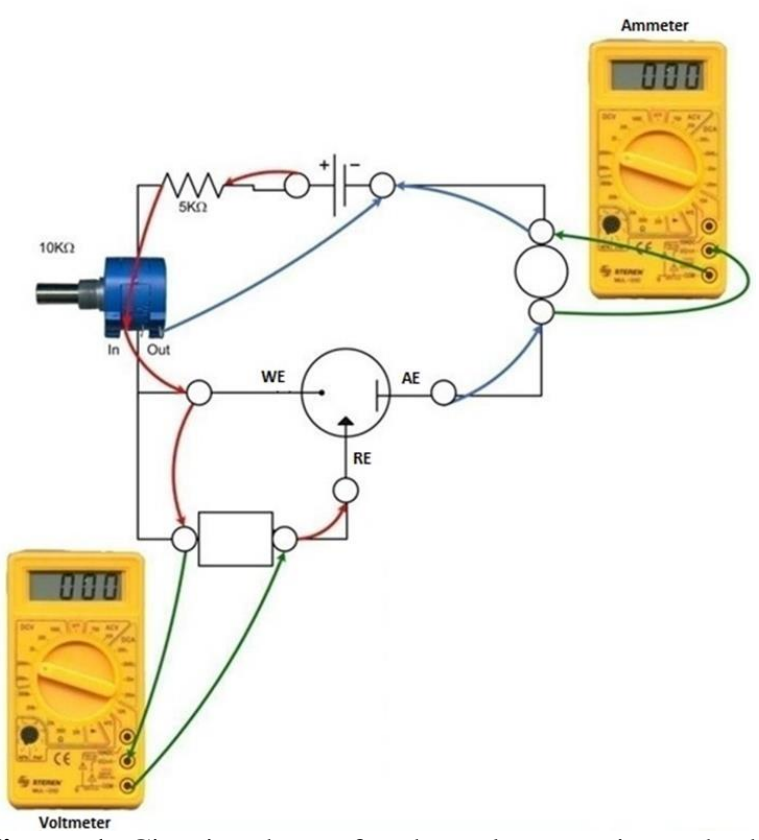

Figure 1. Circuit scheme for the voltammetric method for cadmium quantification using minimal instrumentation ${ }^{17}$.

Figure 2 shows the electrodes design. A microdisc of graphite $(\mathrm{d}=2.03 \mathrm{~mm})$ for writing was employed as a non-commercial working electrode. A bar of the same material was used as auxiliary electrode. The reference was an $\mathrm{Ag}$ wire. Linear potential sweeps were done from -10 to $-1500 \mathrm{mV}$. All the chemical reagents used were for analytic use (Uni-Chem, Serbia).

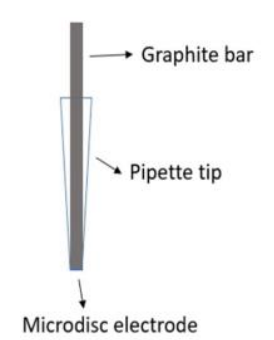

(a)

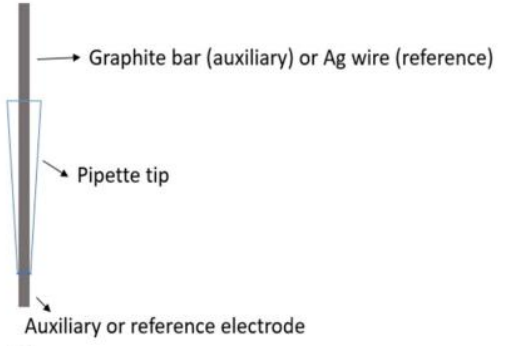

(b)
Figure 2. Electrodes design for the voltammetric method for cadmium quantification using minimal instrumentation: (a) Working electrode, (b) Auxiliary and reference electrodes.

\subsection{Study of conditions for the voltammetric method for cadmium quantification}

Supporting electrolyte concentration and $\mathrm{pH}$ were studied for the voltammetric determination of cadmium. The effect of the $\mathrm{KCl}$ concentration over the limiting current was studied at $0.1,1.0$ and 2.0 
mol L ${ }^{-1}{ }^{19}$. The effect of the $\mathrm{pH}$ was studied at the values of 3, 4 and 5, in the $\mathrm{KCl}$ concentration fixed previously $^{20}$. $\mathrm{pH}$ was fixed using an acetic acid/acetate buffer, which was prepared according to a reported methodology $y^{21}$ Three voltammograms were registered for each $\mathrm{KCl}$ concertation and $\mathrm{pH}$, then, the average limiting current was calculated. Furthermore, simple Analysis of Variance (ANOVA) was used to compare the currents between the different values of $\mathrm{KCl}$ concentration and $\mathrm{pH}$ respectively. A cadmium solution $0.01 \mathrm{~mol} \mathrm{~L}^{-1}$ was use for the study.

\subsection{Linearity}

A calibration curve was built registering the voltammograms to reduce $\mathrm{Cd}^{2+}$ at $0.001,0.005$, $0.007,0.01$ and $0.015 \mathrm{~mol} \mathrm{~L}^{-1}$. Diffusion current (difference between limiting current and residual current) was represented as a function of the concentration, and a linear regression was plotted to obtain the coefficients and the equation of the curve. The curve generated was the result of the mean of three currents for each concentration of $\mathrm{Cd}^{2+22}$.

\subsection{Detection and quantification limits}

In order to determine the detection and quantification limits, 20 voltammograms from the electrolysis medium (without analyte) were generated. The residual current was determined from the voltammograms, and the concentration associated to each value was calculated using the calibration plot. The detection limit was calculated as three times the standard deviation and the quantification limit was calculated as ten times the standard deviation $^{23}$.

\subsection{Precision}

Precision was evaluated as the repeatability of the method. Ten voltammograms were registered at the $\mathrm{Cd}^{2+}$ concentrations: $3 \cdot 10^{-3}, 5 \cdot 10^{-3}$ and $7 \cdot 10^{-3}$ $\mathrm{mol} \mathrm{L} \mathrm{L}^{-1}$. The variation coefficient was calculated as a dispersion criterion ${ }^{23}$. The uncertainty associated to the repeatability was estimated according to the reported metrologic characterization of the potentiostat $^{17}$, where the results showed that it is the most significant source of uncertainty.

\subsection{Accuracy}

Recovery essays were conducted to estimate the accuracy of the method. Solutions of $\mathrm{Cd}^{2+}$ of concentrations: $3 \cdot 10^{-3}, 5 \cdot 10^{-3}$ and $7 \cdot 10^{-3} \mathrm{~mol} \mathrm{~L}^{-1}$ were prepared, voltammograms were registered and then, an amount of $\mathrm{CdCl}_{2}$ corresponding to a concentration of $5 \cdot 10^{-4} \mathrm{~mol} \mathrm{~L}^{-1}$ was added. The voltammograms were registered once more. Experiments were conducted five times, and ANOVA was used to compare the recoveries at different concentrations. Recovery percentage was calculated according to Equation $2^{23}$.

$\% R=\frac{A A-B A}{A} \cdot 100$

where:

$\% \mathrm{R}$ : Recovery percentage

AA: Concentration of the solution after the addition

BA: Concentration of the solution before the addition

A: Concentration of the addition.

\subsection{Data processing}

Statgraphics Centurion XVI and Microsoft Office Excel were used to process the experimental data and the statistical tests.

\section{Results and discussion}

\subsection{Conditions for the voltammetric method for cadmium quantification}

Figure 3 shows the behavior of the limiting current from the $\mathrm{Cd}^{2+}$ reduction with the changes of $\mathrm{KCl}$ concentration. An increase of the current is observed from 0.1 to $1 \mathrm{~mol} \mathrm{~L}^{-1}$ of supporting electrolyte. From $1 \mathrm{~mol} \mathrm{~L}^{-1}$ on, the current maintains almost constant. 


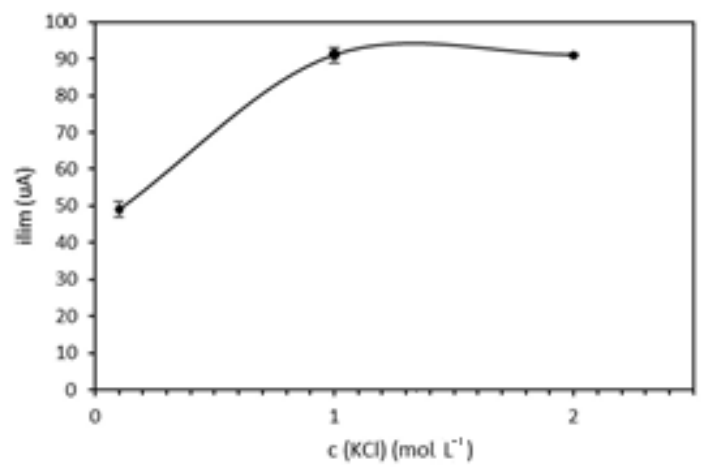

Figure 3. Limiting current for $\mathrm{Cd}^{2+} 0.01 \mathrm{~mol} \mathrm{~L} \mathrm{~L}^{-1}$ reduction as a function of the $\mathrm{KCl}$ concentration in the electrolysis medium.
The Cochran test for the comparison of variances did not show differences statistically significant ( $\mathrm{p}$-value $=0.8995>\alpha=0.05$ ). As a result of comparing the limiting currents at each concentration of $\mathrm{KCl}$, ANOVA showed differences statistically significant between them (pvalue $=0.0000<\alpha=0.05$ ). Table 1 shows the identification of homogeneous currents using a multiple ranges contrast through a LSD test of Fisher for a $95 \%$ of confidence.

Table 1. LSD test of Fisher for the identification of homogeneous limiting currents to different $\mathrm{KCl}$ concentrations (95\% of confidence).

\begin{tabular}{ccccc}
\hline $\mathbf{c}(\mathbf{K C l})$ & Cases & Mean & \multicolumn{2}{c}{ Homogeneous groups } \\
\hline $0.1 \mathrm{~mol} \mathrm{~L}^{-1}$ & 3 & 49.3 & $\mathrm{X}$ & $\mathrm{X}$ \\
$1 \mathrm{~mol} \mathrm{~L}^{-1}$ & 3 & 91.0 & & $\mathrm{X}$ \\
$2 \mathrm{~mol} \mathrm{~L}^{-1}$ & 3 & 91.3 & & \\
\hline
\end{tabular}

The supporting electrolyte allows the analyte to reach predominantly the electrode from the bulk solution by diffusion. This result is mainly because the ions of the electrolyte assume the mass transport by migration. The current will be independent of the supporting electrolyte concentration when the maximum migration mass transport is reached ${ }^{1}$. The currents corresponding to 1 and $2 \mathrm{~mol} \mathrm{~L}^{-1}$ do not show differences statistically significant. Therefore, any of the homogeneous values can be selected to develop the voltammetric electrolysis in order to reduce $\mathrm{Cd}^{2+}$. $\mathrm{KCl} 1 \mathrm{~mol} \mathrm{~L}^{-1}$ was selected.

Figure 4 shows the limiting current as a function of the $\mathrm{pH}$ of the medium. It is possible to observe that the three current values are similar.

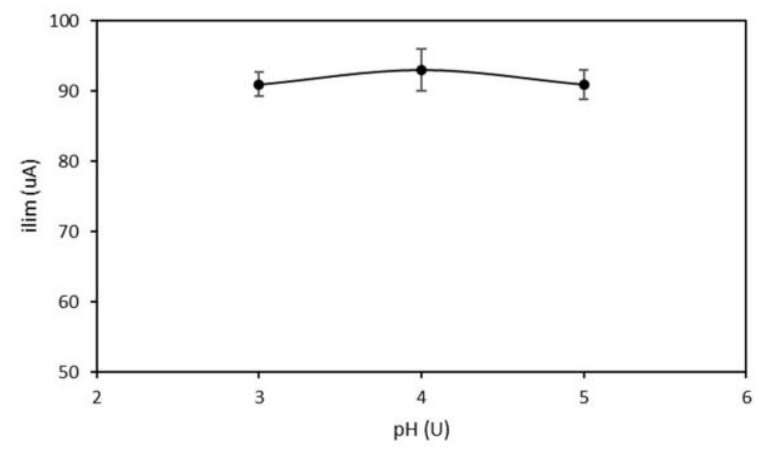

Figure 4. Limiting current for $\mathrm{Cd}^{2+} 0.01 \mathrm{~mol} \mathrm{~L}^{-1}$ reduction as a function of the $\mathrm{pH}$ of the medium.
After comparing the variances, the Cochran test did not show differences statistically significant ( $\mathrm{p}$ value $=0.6047>\alpha=0.05$ ). The comparison of the currents using ANOVA did not show differences statistically significant ( $\mathrm{p}$-value $=0.5632>\alpha=0.05$ ) either. This result demonstrates that it is possible to select any of the $\mathrm{pH}$ values to develop the voltammetric method. The stability of the limiting current matches the species distribution diagram for cadmium ${ }^{24}$, where $\mathrm{Cd}^{2+}$ is stable until $\mathrm{pH} 8$. However, several voltammetric determinations of cadmium are carried out at $\mathrm{pH} 5^{8,25}$; that is the reason why this value was selected to develop the method.

\subsection{Linearity}

Figure 5 shows the voltammograms for the reduction of cadmium at different concentrations using the minimal instrumentation. The sigmoid form of the linear voltammograms is observed and the limiting current increases with the concentration. 


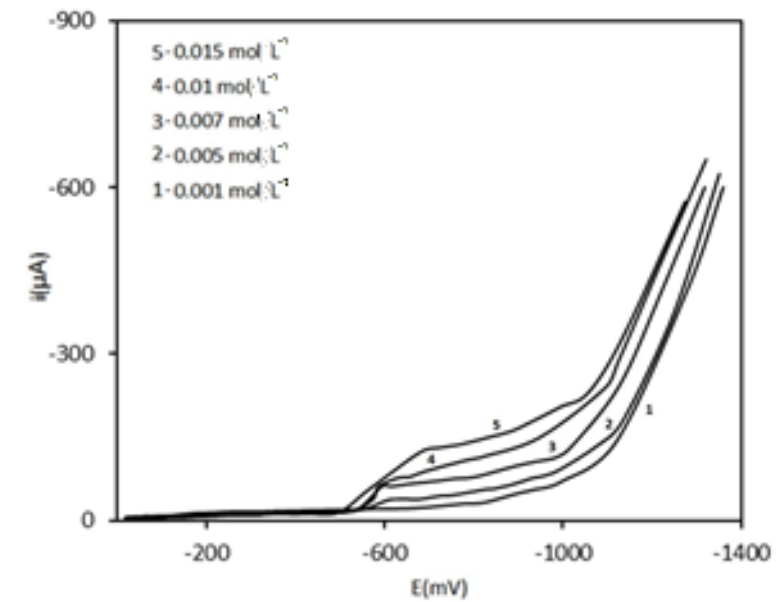

Figure 5. Voltammograms for the $\mathrm{Cd}^{2+}$ reduction using minimal instrumentation.

Figure 6 shows the calibration plot obtained from the voltammograms. The linear range of the voltammetric method is from $10^{-3}$ to $1.5 \cdot 10^{-2} \mathrm{~mol} \mathrm{~L}^{-}$ ${ }^{1}$. The linear correlation coefficient (r) of the curve is 0.9987, which demonstrates a strong linear correlation between the current and the concentration of cadmium. The determination coefficient $\left(\mathrm{R}^{2}\right)$ is 0.9975 , demonstrating that the mathematic model explains the $99.75 \%$ of the variability between both variables. The adjusted coefficient $\left(\mathrm{R}_{\text {adj. }}^{2}\right)$ is 0.9973 .

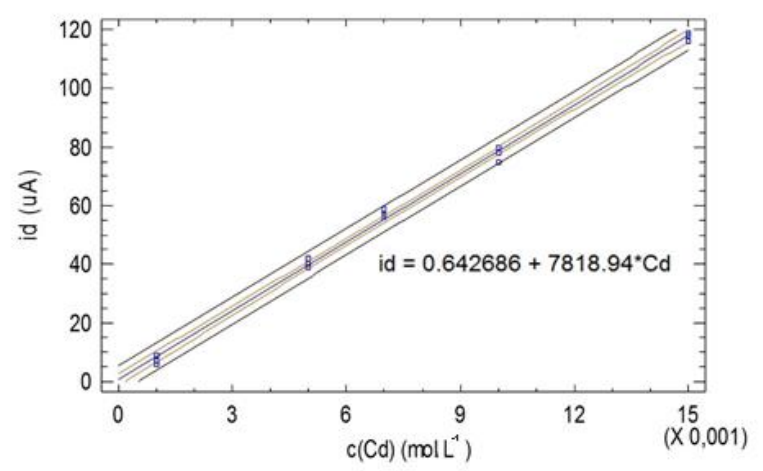

Figure 6. Calibration plot and equation for the voltammetric method for cadmium quantification using minimal instrumentation.

Table 2 shows the ANOVA for the calibration plot for the voltammetric method for cadmium quantification. The $\mathrm{p}$-value is inferior to the significance level $(\alpha=0.05)$, which demonstrates a statistically significant relationship between the current and the concentration.

Table 2. ANOVA for the calibration plot for the voltammetric method for cadmium quantification using minimal instrumentation (95\% of confidence).

\begin{tabular}{cccccc}
\hline Source & SS & DF & MS & F & p-value \\
\hline Model & 20394.9 & 1 & 20394.9 & 5098.9 & 0.0000 \\
Residue & 51.9 & 13 & 3.9 & & \\
Total (Corr.) & 20446.9 & 14 & & & \\
\hline \multicolumn{5}{c}{ SS: Sum of squares, DF: Degrees of freedom, MS: Mean square }
\end{tabular}

A representation of the residues as a function of the concentration allows corroborating the linearity of a calibration plot. Figure 7 does not show a defined tendency of the residues, demonstrating the linearity of the curve in the range of concentrations.

Table 3 shows the regression parameters of the calibration plot for the $95 \%$ of confidence. Errors and the p-values associated with the slope and the intercept are the most important.

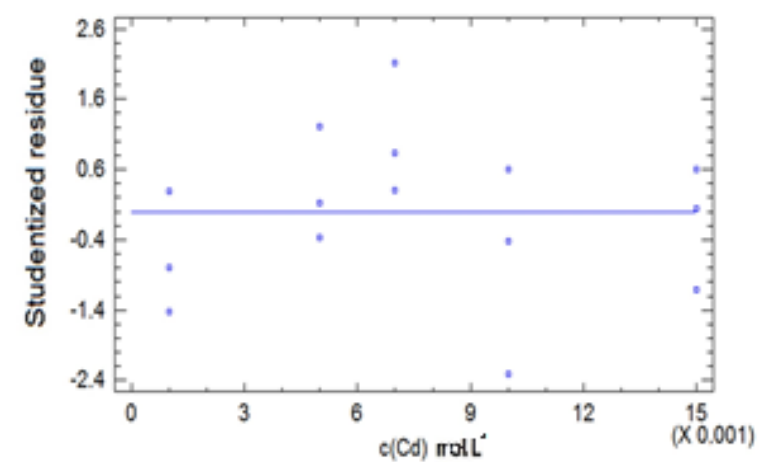

Figure 7. Studentized residues as a function of the $\mathrm{Cd}^{2+}$ concentration for the calibration plot for the voltammetric method for cadmium quantification using minimal instrumentation. 
Table 3. Parameters of the calibration plot regression for the voltammetric method for cadmium quantification using minimal instrumentation (95\% of confidence).

\begin{tabular}{ccccc}
\hline & Minimal Square & Standard & Statistical & \\
\hline Parameter & Estimated & Error & T & p-value \\
\hline Intercept & 0.6427 & 0.9794 & 0.6562 & 0.5231 \\
Slope & 7818.94 & 109.50 & 71.4071 & 0.0000 \\
\hline
\end{tabular}

The p-value of the intercept is superior to the level of significance $(\alpha=0.05)$, indicating that the intercept is statistically equal to zero. It demonstrates the adequate correction of the limiting current by the subtraction of the residual current. The slope of the calibration plot indicates the sensibility of the method. The value reported is $7818.94 \mu \mathrm{A} \cdot \mathrm{mol} \mathrm{L}^{-1}$, which demonstrates a high variation of the current with $\mathrm{Cd}^{2+}$ concentration changes.

\subsection{Detection and quantification limits}

Table 4 shows the detection and quantification limits of the voltammetric method for the quantification of cadmium using minimal instrumentation. The detection limit is in the order commonly reported for linear voltammetry $\left(10^{-4}\right.$ $\left.\mathrm{mol} \mathrm{L}^{-1}\right)^{1}$.

Table 4. Detection and quantification limits of the voltammetric method for cadmium quantification using minimal instrumentation.

\begin{tabular}{cc}
\hline Limit & Value \\
\hline Detection & $3 \cdot 10^{-4} \mathrm{~mol} \mathrm{~L}^{-1}$ \\
Quantification & $10^{-3} \mathrm{~mol} \mathrm{~L}^{-1}$ \\
\hline
\end{tabular}

\subsection{Precision}

Table 5 shows the results of the repeatability for three cadmium concentrations. Results of 10 essays and the statistical parameters as well as uncertainty are shown.

Table 5. Repeatability of the voltammetric method for the cadmium quantification using minimal instrumentation.

\begin{tabular}{cccc}
\hline & \multicolumn{3}{c}{ Concentration $\left(\mathbf{m o l ~ L}^{-\mathbf{1}}\right)$} \\
\cline { 2 - 4 } Essay & $\mathbf{0 . 0 0 3}$ & $\mathbf{0 . 0 0 5}$ & $\mathbf{0 . 0 0 7}$ \\
\hline $\mathbf{1}$ & 0.0033 & 0.0050 & 0.0072 \\
$\mathbf{2}$ & 0.0031 & 0.0049 & 0.0073 \\
$\mathbf{3}$ & 0.0030 & 0.0050 & 0.0070 \\
$\mathbf{4}$ & 0.0033 & 0.0050 & 0.0073 \\
$\mathbf{5}$ & 0.0030 & 0.0054 & 0.0070 \\
$\mathbf{6}$ & 0.0033 & 0.0052 & 0.0072 \\
$\mathbf{7}$ & 0.0035 & 0.0050 & 0.0070 \\
$\mathbf{8}$ & 0.0033 & 0.0050 & 0.0070 \\
$\mathbf{9}$ & 0.0033 & 0.0052 & 0.0072 \\
$\mathbf{1 0}$ & 0.0033 & 0.0052 & 0.0072 \\
\hline Mean & 0.0033 & 0.0051 & 0.0071 \\
SD & 0.00019 & 0.00017 & 0.00011 \\
$\mathbf{C V}$ & $5.8 \%$ & $3.3 \%$ & $1.5 \%$ \\
Uncertainty & $1.2 \cdot 10^{-4} \mathrm{~mol} \mathrm{~L}^{-1}$ & $10^{-4} \mathrm{~mol} \mathrm{~L}^{-1}$ & $7 \cdot 10^{-5} \mathrm{~mol} \mathrm{~L}^{-1}$ \\
\hline
\end{tabular}

SD: Standard deviation, CV: Coefficient of variation 
The deviation of the results obtained under similar conditions (repeatability) for voltammetric methods is due to fundamentally to the reproducibility of the electrode surface. The electrolysis is a surface phenomenon, and the surface homogeneity influences the current repeatability. When a new electrode surface is generated, it is not exactly equal to the previous one. Therefore, both the amount and shape of the active sites where the electrolysis occurs are not equal either. Consequently, it provokes the measured currents between different electrode surfaces to differ in some degree. Nowadays, vitreous carbon is the most commonly used material as carbon electrode due to the homogeneity of the surface and therefore, the good repeatability of the current values ${ }^{26}$. However, the non-commercial graphite electrode used in this voltammetric method shows an acceptable repeatability.
Uncertainty diminishes with the increase of the concentration. It bears correspondence to results presented by other authors ${ }^{27,28}$. This tendency is associated with the major magnitude of the errors when the concentration diminishes ${ }^{29}$.

\subsection{Accuracy}

Table 6 shows the recovery percentages for cadmium quantification using minimal instrumentation. An amount of $\mathrm{CdCl}_{2}$ was added to standard solutions to increase concentration in $0.0005 \mathrm{~mol} \mathrm{~L}^{-1}$. In all cases, the recovery percentages were between 80 and $110 \%$; the range reported by the Guidelines for Validation of Chemical Testing Methods ${ }^{23}$. This demonstrates a good accuracy for cadmium quantification by means of the voltammetric method with the noncommercial electrodes and potentiostat.

Table 6. Recovery percentages for the voltammetric cadmium quantification using minimal instrumentation.

\begin{tabular}{|c|c|c|c|c|c|c|}
\hline Concentration & Essay & $\mathbf{A A}$ & BA & $\mathbf{A}$ & $\% \mathrm{R}$ & \\
\hline \multirow{5}{*}{$0.003 \mathrm{~mol} \mathrm{~L}^{-1}$} & 1 & 0.0035 & 0.0030 & 0.0005 & 104.7 & \multirow{2}{*}{$\begin{array}{c}\% \mathrm{R}_{\text {mean }} \\
101.2\end{array}$} \\
\hline & 2 & 0.0038 & 0.0033 & 0.0005 & 106.9 & \\
\hline & 3 & 0.0038 & 0.0033 & 0.0005 & 100.5 & \multirow{3}{*}{$\begin{array}{c}\mathrm{CV} \\
8.30 \%\end{array}$} \\
\hline & 4 & 0.0037 & 0.0033 & 0.0005 & 86.84 & \\
\hline & 5 & 0.004 & 0.0035 & 0.0005 & 106.9 & \\
\hline & Essay & $\mathbf{A A}$ & BA & $\mathbf{A}$ & $\% R$ & \multirow{3}{*}{$\begin{array}{c}\% \mathrm{R}_{\text {mean }} \\
99.64\end{array}$} \\
\hline \multirow{6}{*}{$0.005 \mathrm{~mol} \mathrm{~L}^{-1}$} & 1 & 0.0059 & 0.0054 & 0.0005 & 99.36 & \\
\hline & 2 & 0.0055 & 0.0050 & 0.0005 & 94.37 & \\
\hline & 3 & 0.0059 & 0.0054 & 0.0005 & 100.8 & \multirow{3}{*}{$\begin{array}{c}\text { CV } \\
6.10 \%\end{array}$} \\
\hline & 4 & 0.0054 & 0.0049 & 0.0005 & 109.2 & \\
\hline & 5 & 0.0056 & 0.0051 & 0.0005 & 94.49 & \\
\hline & Essay & $\mathbf{A A}$ & BA & $\mathbf{A}$ & $\% \mathrm{R}$ & \multirow{3}{*}{$\begin{array}{c}\% \mathrm{R}_{\text {mean }} \\
99.52\end{array}$} \\
\hline \multirow{5}{*}{$0.007 \mathrm{~mol} \mathrm{~L}^{-1}$} & 1 & 0.0077 & 0.0073 & 0.0005 & 99.52 & \\
\hline & 2 & 0.0077 & 0.0072 & 0.0005 & 94.22 & \\
\hline & 3 & 0.0075 & 0.0070 & 0.0005 & 94.47 & \multirow{3}{*}{$\begin{array}{c}\mathrm{CV} \\
6.30 \%\end{array}$} \\
\hline & 4 & 0.0078 & 0.0073 & 0.0005 & 109.64 & \\
\hline & 5 & 0.0076 & 0.0071 & 0.0005 & 99.77 & \\
\hline
\end{tabular}

AA: Concentration of the solution after the addition, BA: Concentration of the solution before the addition, A: Concentration of the addition, \%R: Recovery percentages.

The Cochran test did not show differences statistically significant between the variances of the recovery percentages in the three concentrations ( $p$-value $=0.6260>\alpha=0.05$ ). The comparison of the recovery percentages in the three concentrations using ANOVA did not show differences statistically significant $(\mathrm{p}$-value $=0.9183>\alpha=0.05)$.
Thus, it demonstrates that the accuracy does not vary with concentration for the levels of these essays. 


\section{Conclusions}

A voltammetric method for the quantification of cadmium using minimal instrumentation was developed. Supporting electrolyte $\mathrm{KCl} 1 \mathrm{~mol} \mathrm{~L}^{-1}$ and $\mathrm{pH} 5$ were selected as working conditions. Regression coefficients superior to $99 \%$ showed a good linearity of the method using the noncommercial electrodes and the manual homemade potentiostat. The limits of detection and quantification were in correspondence with the results reported for the linear sweep voltammetry. Results showed an acceptable repeatability. Uncertainty associated with the cadmium concentration diminished with the increase of concentration. A good accuracy was observed, with recovery percentages complying with the established standards. The accuracy was independent of the concentration for the studied range.

\section{Acknowledgments}

Authors are thankful to Geisa Dávila for the language correction.

\section{References}

[1] Skoog, D. A., Holler, F. J., Crouch, S. R., Principles of Instrumental Analysis, McGraw Hill, New York, 6th ed., 2008, Ch. 25.

[2] Bard, A. J., Faulkner, L. R., Electrochemical Methods, John Wiley \& Sons Inc., New York, 2001, Ch 6.

[3] Kounaves, S., Voltammetric Techniques, In: Handbook of Instrumental Techniques for Analytical Chemistry, Settle, F., ed., Prentice Hall, New York, 1997, Ch 37.

[4] Leon-Rojas, C., Optimización y puesta a punto de un método de mineralización de muestras ambientales para la determinación de ultratrazas de platino, rodio y paladio, Rev. Int. Contam. Amb. 21 (3) (2005) 107-113. Available in: <https://www.redalyc.org/articulo.oa>.

[5] Alvarado-Gámez, A. L., Campos-Fernandéz, J., Development and validation of a voltammetry method to determine traces of iron in water and other matrixes, Port. Electrochim. Acta 23 (1) (2005) 209-221.
[6] Espinosa-Castellón, E. R., Alvarado-Gámez, A. L., Desarrollo y validación de un método voltamperométrico para determinar estaño total en agua, Rev. Int. Contam. Ambie. 28 (1) (2012) 6172.

[7] Farghaly, O. A., Abdel Hameed, R. S., AbuNawwas, H., Analytical application using modern electrochemical techniques, Int. J. Electrochem. Sci. 9 (2014) 3287-3318.

[8] Moreno, Y. L., García, J. M., Chaparro, S. P., Cuantificación voltamétrica de plomo y cadmio en papa fresca, Rev. U. D. C. A. Act. \& Div. Cient. 19 (1) (2016) 97-104.

[9] Nordberg, G., Metals: Chemical properties and toxicity, In: Encyclopedia of health and security in the work, Mayer, J., ed., Chantal Dufresne BA, Geneva, 1998, Ch. 63.

[10] Hernández Moreno, D., García Fernandéz, M. A., Alonso Díaz, J., Melgar Riol, M. J., Pérez López, M., Concentraciones de metales pesados (plomo y cadmio) en conservas de almeja, berberecho y navaja comercializadas en España, Ciencia y Tecnología Alimentaria 4 (3) (2004) 197-205.

[11] Chang, C. Y., Yu, H. Y., Chen, J. J., Li, F. B., Zhang, H. H., Liu, C. P., Accumulation of heavy metals in leaf vegetables from agricultural soils and associated potential health risks in the Pearl River Delta, South China, Environ. Monit. Assess. 186 (3) (2014) 1547-1560. https://doi.org/10.1007/s10661-013-3472-0.

[12] Zhenning, Y., Lub, Y., Li, X., Silver ionselective electrodes based on bis(dialkyldithiocarbamates) as neutral ionophores, Sens. Actuators B 122 (1) (2007) 174181. https://doi.org/10.1016/j.snb.2006.05.020.

[13] Guo, S. X., Khoo, S. B., Highly selective and sensitive determination of silver(I) at a poly(8mercaptoquinoline) film modified glassy carbon electrode, Electroanalysis 11 (12) (1999) 891-898. https://doi.org/10.1002/(SICI)15214109(199908)11:12\%3C891::AIDELAN891\%3E3.0.CO;2-9.

[14] Khan, F., Khanam, A., Study of complexes of cadmium with some L-amino acids and vitamin-C 
by voltammetric technique, Ecl. Quím. J. 33 (2) (2008) 29-36. https://doi.org/10.1590/S010046702008000200004 .

[15] Economou, A., Bolis, S.D., Efstathiou, C.E., Volikakis, G.J., A "virtual" electroanalytical instrument for square wave voltammetry, Analytica Chimica Acta 467 (2) (2002) 179-188. https://doi.org/10.1016/S0003-2670(02)00191-5.

[16] Baltuano, O., Hernández, Y., Montoya, E., Desarrollo de un potenciostato analítico de bajo costo y altas prestaciones, Informe Científico 12 (2012) 165-169.

[17] Vilasó, J. E., Arada, M. A., Baeza, J. A., Céspedes, A., Construction and metrological characterization of a minimal instrumentation micropolarograph, Port. Electrochim. Acta 34 (5) (2016) 309-320. https://doi.org/10.4152/pea.201605309.

[18] Nogueira, C. A., Delmas, F., New flowsheet for the recovery of cadmium, cobalt and nickel from spent $\mathrm{Ni}-\mathrm{Cd}$ batteries by solvent extraction, Hydrometallurgy $52 \quad$ (3) (1999) 267-287. https://doi.org/10.1016/S0304-386X(99)00026-2.

[19] Copeland, T. R., Christie, J. H., Skogerboe, R. K., Osteryoung, R.A., Effect of supporting electrolyte concentration in pulsed stripping voltammetry at the thin film mercury electrode, Analytical Chemistry 45 (6) (1973) 995-996. https://doi.org/10.1021/ac60328a017.

[20] Zeng, A., Liu, E., Tan, S. N., Zhang, S., Gao, J., Stripping voltammetric analysis of heavy metals at nitrogen doped diamond-like carbon film electrodes, Electroanalysis 14 (18) (2002) 12941298. https://doi.org/1040-0397/02/1809-1294.

[21] Lurie, J., Handbook of Analytical Chemistry, Mir Publishers, Moscow, 1975.

[22] Dieker, J. W., Van Der Linden, W. E., Poppe, $\mathrm{H}$., Behaviour of solid electrodes in normal and differential pulse voltammetric methods, Talanta 25 (1978) 151-155. https://doi.org/10.1016@00399140(78)80104-0.

[23] NC Guideline, Guidelines for validation of chemical testing methods, NC, NC Proyecto (2001) 23.
[24] Choi, J., Ide, A., Truong, Y. B., Kyratzis, I. L., Caruso, R. A., High surface area mesoporous titanium-zirconium oxide nanofibrous web: a heavy metal ion adsorbent, J. Mater. Chem. A (2013) 5847-5853. https://doi.org/10.1039/c3ta00030c.

[25] Rajawat, D. S., Kumar, N., Satsangee, S. P., Trace determination of cadmium in water using anodic stripping voltammetry at a carbon paste electrode modified with coconut shell powder, Journal of Analytical Science and Technology 5 (19) (2014). https://doi.org/10.1186/s40543-0140019-0.

[26] Uslu, B., Ozkan, S. A., Solid electrodes in Electroanalytical Chemistry: Present applications and prospects for high throughput screening of drug compounds, Combinatorial Chemistry \& High Throughput Screening 10 (7) (2007) 495-513. https://doi.org/1386-2073/07.

[27] Thomson, M., The Characteristic Function, a method-specific alternative to the Horwitz Function, Journal of AOAC International 95 (6) (2012) 1803-1806.

[28] Hechavarría, A., Arada, M.A., Estimación de la incertidumbre de la medición en análisis químico, un caso de estudio, Rev. Cubana Quím. 29 (1) (2017) 54-72.

[29] EURACHEM/CITAC Guideline, Quantifying uncertainty in analytical measurement, EURACHEM/CITAC, CG4 (2000) 120. 